\title{
Echocardiographic Assessment of Mitral Stenosis: Key Learning Points for Fellows/Residents in Training
}

\section{Ravi Raj}

\begin{abstract}
Mitral stenosis is most commonly due to rheumatic heart disease, even in western countries. Transthoracic echocardiography is the modality of choice for establishing diagnosis, underlying cause, assessment of severity, staging of disease, valve morphology and other associated lesions. Transesophageal echocardiography is recommended in patients considered for percutaneous balloon mitral valvotomy to rule out LA clot, significant MR and to better assess mitral valve morphology. Three-dimensional echocardiography is now increasingly used for estimating mitral valve area and suitability for percutaneous balloon mitral valvotomy. We provide a brief discussion on echocardiographic assessment of mitral stenosis.
\end{abstract}

Keywords: Rheumatic mitral stenosis, Transthoracic echocardiography, Transesophageal echocardiography, Threedimensional echocardiography, Mitral valve.

How to cite this article: Raj R. Echocardiographic Assessment of Mitral Stenosis: Key Learning Points for Fellows/Residents in Training. J Perioper Echocardiogr 2015;3(1):17-24.

\section{Source of support: Nil}

Conflict of interest: None

\section{MITRAL VALVE (RELEVANT ANATOMY)}

Mitral valve or left atrioventricular valve is a bicuspid valve consisting of a larger anterior (aortic or septal) leaflet and a smaller posterior (mural or ventricular) leaflet. Although larger in surface area, the anterior leaflet attaches to only $1 / 3$ rd of mitral annulus, whereas the posterior or smaller leaflet attaches to rest $2 / 3$ rd of the mitral annulus. Both the mitral leaflets meet at anterolateral and posteromedial commissures. The anterior mitral leaflet is in fibrous continuity with aortic valve through the aorto-mitral curtain.

Both the leaflets of mitral valve are supported by two groups of papillary muscles, i.e. anterolateral and posteromedial groups via chordae tendinae. The chordae

\footnotetext{
Senior Resident

Department of Anesthesia and Intensive Care, Postgraduate Institute of Medical Education and Research, Chandigarh, India

Corresponding Author: Ravi Raj, Senior Resident, Department of Anesthesia and Intensive Care, Postgraduate Institute of Medical Education and Research, Chandigarh, India, Phone: 01722755065, e-mail: drraviraj2007@gmail.com
}

tendinae are fibrous chord like structures arising from papillary muscles and attaching on the under surface of mitral leaflets. Both the mitral leaflets receive chordae attachments from both the groups of papillary muscles. The chordae tendinae are further categorized into three groups: first order (attaches on the free margins of the leaflets), second order (insert few to several mm back from the free edge of the leaflets) and third order (insert at the base of posterior mitral leaflet only).

A few classification systems like carpentier, modified carpentier and modified duran have been introduced for uniformity in description of lesions and clear communication between different physicians managing the patient. ${ }^{1-3}$ Carpentier system is most widely used and divides each mitral leaflet into 3 segments, i.e. A1, A2, A3 for anterior and P1, P2 and P3 for posterior mitral leaflet respectively. A1, P1 represent anterolateral segments, A2, $\mathrm{P} 2$ represent middle and $\mathrm{A} 3, \mathrm{P} 3$ represent posteromedial segments.

\section{MITRAL STENOSIS (ETIOLOGY AND PATHO- PHYSIOLOGY)}

Rheumatic heart disease is the most common cause of mitral stenosis, even in western countries. ${ }^{4,5}$ Rheumatic mitral stenosis is characterized by commissural fusion and leaflet thickening. There is characteristic doming of anterior mitral leaflet during diastole giving typical hockey-stick appearance (Fig. 1, Video 1). Calcification can be seen in chronic rheumatic disease and typically starts from leaflet edges, commissures and spreads to involve other parts of mitral valve apparatus. Subvalvular apparatus (chordae tendinae and papillary muscles) may also get thickened, fused and calcified in some cases.

Senile calcific mitral stenosis is increasingly seen in western countries with aging population. It is seen more commonly in elderly females. It is a degenerative disease with calcification starting in posterior annulus and spreading to involve other parts of annulus and leaflets. It may be associated with senile calcific aortic stenosis. In contrast to rheumatic mitral stenosis, leaflet edges are usually free of disease in senile calcific mitral stenosis. Senile MS is rarely amenable to valve repair and will require valve replacement in severe advanced disease. 


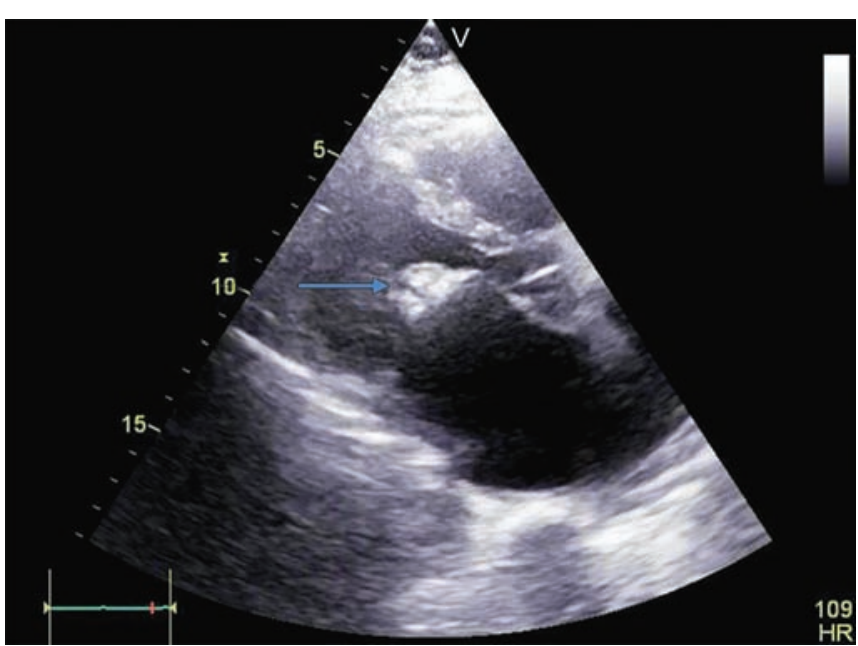

Fig. 1: Parasternal long axis view showing characteristic doming of anterior mitral leaflet giving hockey stick appearance. Please note thickening and calcification at tip of anterior mitral leaflet (arrow) (Video 1)

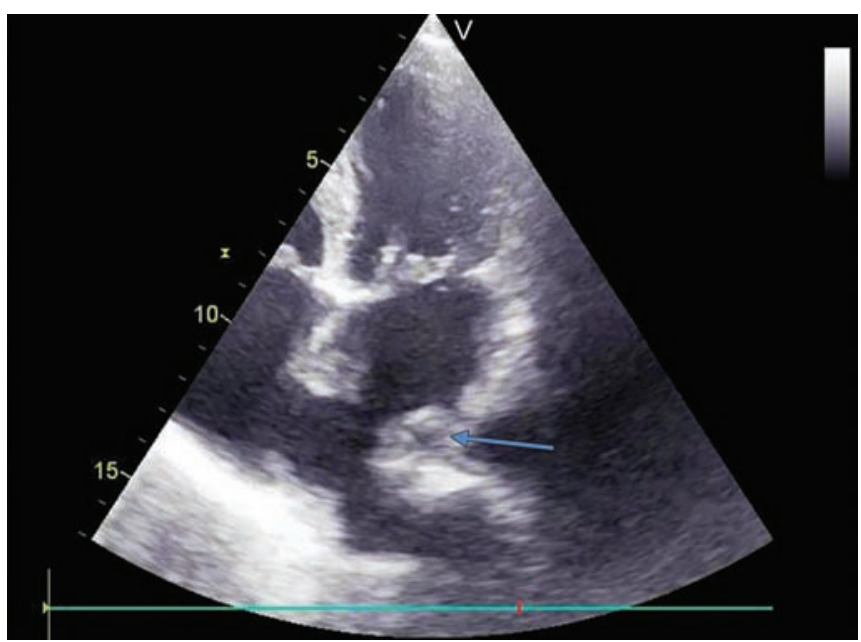

Fig. 2: Transthoracic apical 4 chamber view showing clot (arrow) in left atrium in a patient with mitral stenosis (Video 2). Please note there is an echo dropout (artefact) in interatrial septum and not atrial septum defect (ASD)

Table 1: Mitral stenosis-stages of the disease process

\begin{tabular}{|c|c|}
\hline Stage & Description \\
\hline $\begin{array}{l}\text { Stage } A \\
\text { (At risk) }\end{array}$ & Mild doming of valve during diastole, asymptomatic, normal transmitral pressure gradients \\
\hline $\begin{array}{l}\text { Stage B } \\
\text { (Progressive MS) }\end{array}$ & $\begin{array}{l}\text { Rheumatic valve changes, asymptomatic, increased transmitral gradients, mitral valve area } \\
>1.5 \mathrm{~cm}^{2} \text {, mild to mod LA enlargement, normal PA pressures }\end{array}$ \\
\hline $\begin{array}{l}\text { Stage C } \\
\text { (Asymptomatic severe MS) }\end{array}$ & $\begin{array}{l}\text { Rheumatic valve changes, asymptomatic, increased transmitral pressure gradients, mitral valve area } \\
<1.5 \mathrm{~cm}^{2}(<1.0 \text { - very severe MS), severe LA enlargement, elevated PA pressures }\end{array}$ \\
\hline $\begin{array}{l}\text { Stage D } \\
\text { (Symptomatic severe MS) }\end{array}$ & $\begin{array}{l}\text { Rheumatic valve changes, symptomatic (dyspnea on exertion, syncope), increased transmitral } \\
\text { pressure gradients, mitral valve area }<1.5 \mathrm{~cm}^{2}(<1.0 \text { - very severe MS), severe LA enlargement, } \\
\text { elevated PA pressures. }\end{array}$ \\
\hline
\end{tabular}

Other rare causes of mitral stenosis include inflammatory (e.g. systemic lupus erythematosus), carcinoid, infiltrative disorders and congenital mitral stenosis (Box 1).

Box 1: Causes of mitral stenosis

- Rheumatic heart disease

- $\quad$ Senile calcific MS

- Systemic lupus erythematosus

- Infiltrative disorders (amyloidosis)

- Carcinoid

- $\quad$ Congenital MS

- Commissural fusion

- Supramitral ring

- Parachute mitral valve (may be part of Shone's complex)

- Hammock mitral valve

Severe MS leads to stagnation of blood flow in left atrium and predisposes to clot formation (Fig. 2, Video 2). Left atrial appendage is the most common site for clot formation but may be seen in posterior wall of left atrium as well and may block pulmonary venous drainage in some cases. Loss of atrial contraction (atrial fibrillation) increase the frequency of clot formation while associated significant mitral regurgitation reduces the chances of clot formation. Left atrial enlargement is a common finding in patients with MS. Left atrial pressures increase as a result of decreased forward flow and is transmitted back on pulmonary vasculature and manifests as pulmonary hypertension. Tricuspid regurgitation may be due to rheumatic involvement of tricuspid valve but is more commonly functional as a result of increased right sided pressures (Fig. 3, Video 3).

Normal mitral valve area is 4 to $6 \mathrm{~cm}^{2}$. Symptoms related to MS start appearing with exercise when mitral valve area is reduced to 1.5 to $2.5 \mathrm{~cm}^{2}$ and at rest with mitral valve area less than $1.5 \mathrm{~cm}^{2}$. According to American College of Cardiology and American Heart Association guidelines on valvular heart disease, patients with mitral stenosis are divided into 4 stages $^{6}$ (Table 1 ).

\section{TWO-DIMENSIONAL ECHO ASSESSMENT}

Two-dimensional transthoracic echocardiography (TTE) is class I recommendation (ACC/AHA 2014 guidelines for valvular heart disease) for establishing diagnosis, underlying cause, assessment of severity, staging of disease, valve morphology (suitability for balloon mitral valvotomy) and other associated lesions. ${ }^{6}$ 


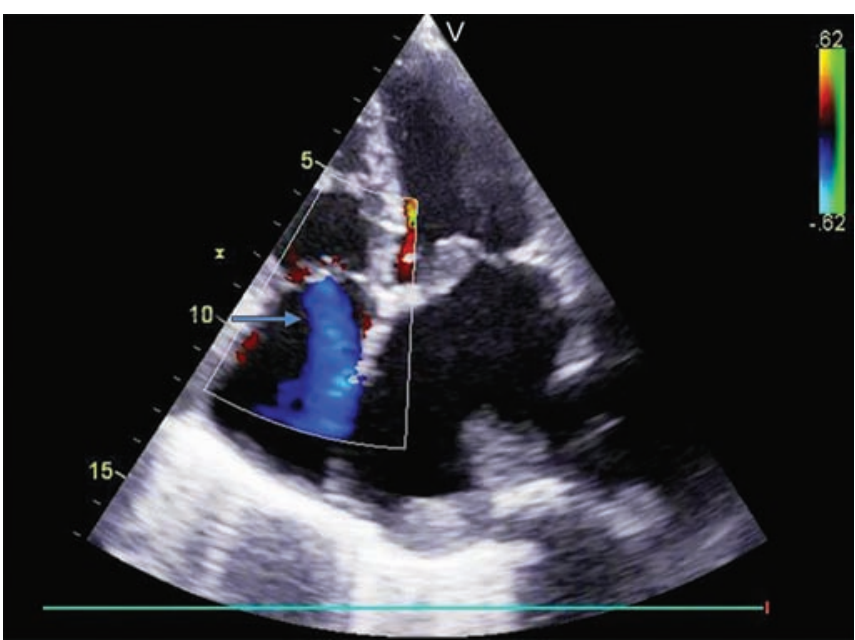

Fig. 3: Apical 4 chamber view with color Doppler showing tricuspid regurgitation (arrow) in a patient with mitral stenosis (Video 3)

\section{Assessing the Severity of Mitral Stenosis (Indices of Severity):}

1. Pressure gradient (Box 2): The estimation of the diastolic pressure gradient is Level 1 recommendation (combined American Society of Echocardiography and European Association of Echocardiography guidelines) for assessment of severity of mitral stenosis. ${ }^{7}$ Pressure gradient is estimated by application of continuous wave Doppler across the mitral valve in apical 4 chamber view to measure higher velocities anticipated (Fig. 4). As peak gradient across mitral valve may be influenced by compliance of both left atrium and left ventricle, mean pressure gradient estimation is recommended (Table 2).

The pressure gradient across the mitral valve may be affected by heart rate, cardiac output and associated mitral regurgitation. In case of atrial fibrillation, an average gradient of 5 cycles with least $R-R$ variation and heart rate as close to normal should be calculated.

Box 2: Pressure gradient (key learning points)

- $\quad$ Level 1 recommendation (ASE/EAE guidelines valvular stenosis).

- Mean gradient estimation recommended.

- Influenced by heart rate, cardiac output and associated mitral regurgitation.

- In case of atrial fibrillation, average of 5 cycles used.

2. Mitral valve area by planimetry (Box 3): Planimetry method is also Level I recommendation (combined ASE/EAE guidelines on valvular stenosis) for assessing severity of mitral stenosis. ${ }^{7}$ It is measured by tracing the mitral valve orifice in parasternal short axis view during mid-diastole (Fig. 5, Video 4). This method is not influenced by flow conditions, compliance of chambers and thus considered better than other methods by some authors. However, it may not be practically feasible in patients with calcification involving leaflet tips. Also, care should be

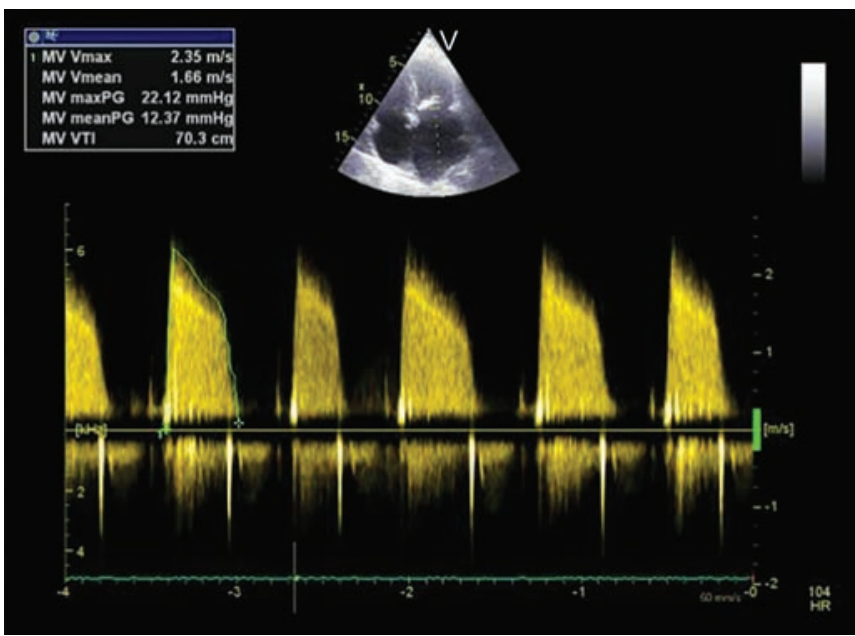

Fig. 4: Estimation of pressure gradient across mitral valve using continuous wave Doppler in apical 4 chamber view in a patient with severe mitral stenosis

Table 2: Severity of mitral stenosis based on echocardiographic variables

\begin{tabular}{lll}
\hline Severity of MS & $\begin{array}{l}\text { Mean pressure } \\
\text { gradient }\end{array}$ & Mitral valve area \\
\hline Mild & $<5 \mathrm{~mm} \mathrm{Hg}$ & $1.5-2.5 \mathrm{~cm}^{2}$ \\
Moderate & $5-10 \mathrm{~mm} \mathrm{Hg}$ & $1-1.5 \mathrm{~cm}^{2}$ \\
Severe & $>10 \mathrm{~mm} \mathrm{Hg}$ & $<1 \mathrm{~cm}^{2}$ \\
\hline
\end{tabular}

taken so that measurement plane is perpendicular to the mitral orifice and measurement taken at the level of leaflet tips. Three-dimensional echocardiography, if available is better to optimize measurement plane and level..$^{8-10}$

Box 3: Planimetry (key learning points)

- Level 1 recommendation (ASE/EAE guidelines valvular stenosis).

- Parasternal short axis view

- Tracing the valve orifice during mid-diastole

- Theoretically better than other methods

- May be practically difficult (calcifications, poor acoustic windows).

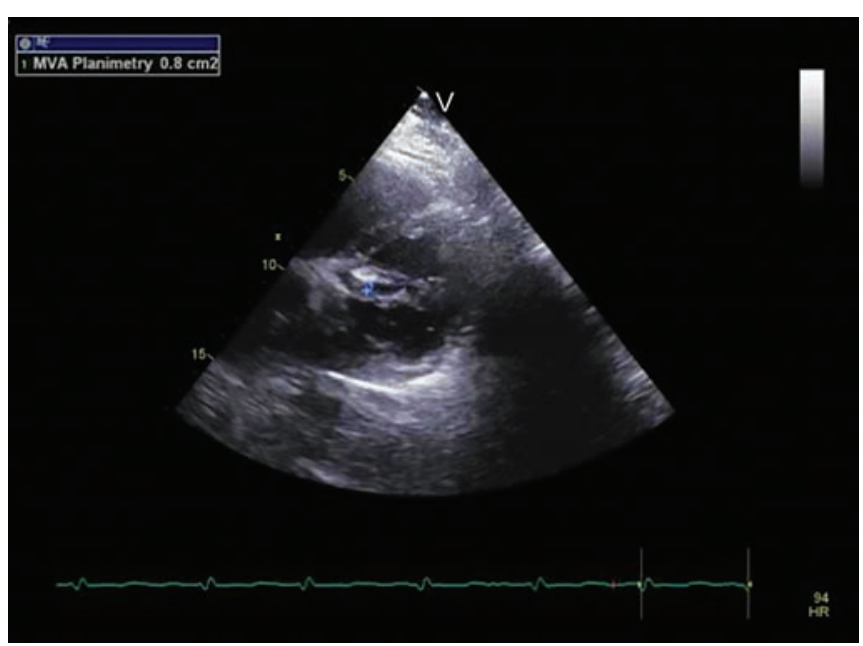

Fig. 5: Mitral valve area calculation by planimetry in parasternal short axis view by tracing the leaflet edges during middiastole (Video 4) 
3. Pressure half-time (Box 4): The estimation of mitral valve area using pressure half-time method is also Level I recommendation (combined ASE/EAE guidelines on valvular stenosis) for assessing severity of mitral stenosis. ${ }^{7}$ The calculation of mitral valve area by pressure half time method is based on the principle that the decline of diastolic transmitral velocity is inversely proportional to mitral valve area. The time interval in milliseconds between peak early diastolic velocity to the point it reaches half maximum velocity is termed half time ${ }^{11}\left(\mathrm{~T}_{1 / 2}\right)$ (Fig. 6). Mitral valve area (in $\mathrm{cm}^{2}$ ) is calculated as $220 / \mathrm{T}_{1 / 2}$.

Box 4: Pressure half-time method (key learning points)

- $\quad$ Level 1 recommendation (ASE/EAE guidelines valvular stenosis).

- $\quad \mathrm{T}_{1 / 2}$ is time interval in milliseconds from peak early diastolic mitral velocity to half peak velocity.

- $\quad \mathrm{MV}$ area $=220 / \mathrm{T}_{1 / 2}$

- $\quad$ Easy to perform

- Influenced by relative compliance of left atrium and left ventricle

Although easy to perform, the estimation of mitral valve area by this method is influenced by early diastolic mitral pressure gradient and left atrial and left ventricular compliance. This method may not be reliable in patients with associate aortic regurgitation or in elderly patients with senile calcific MS and associated diastolic dysfunction. ${ }^{12-14}$

4. Continuity equation (Box 5): The calculation of mitral valve area by using continuity equation is Level 2 recommendation (combined ASE/EAE guidelines on valvular stenosis). ${ }^{7}$ This method is based on the principle of conservation of mass, i.e. stroke volume across mitral valve is equal to stroke volume across left ventricle outflow tract (LVOT), assuming no mitral regurgitation or aortic regurgitation.

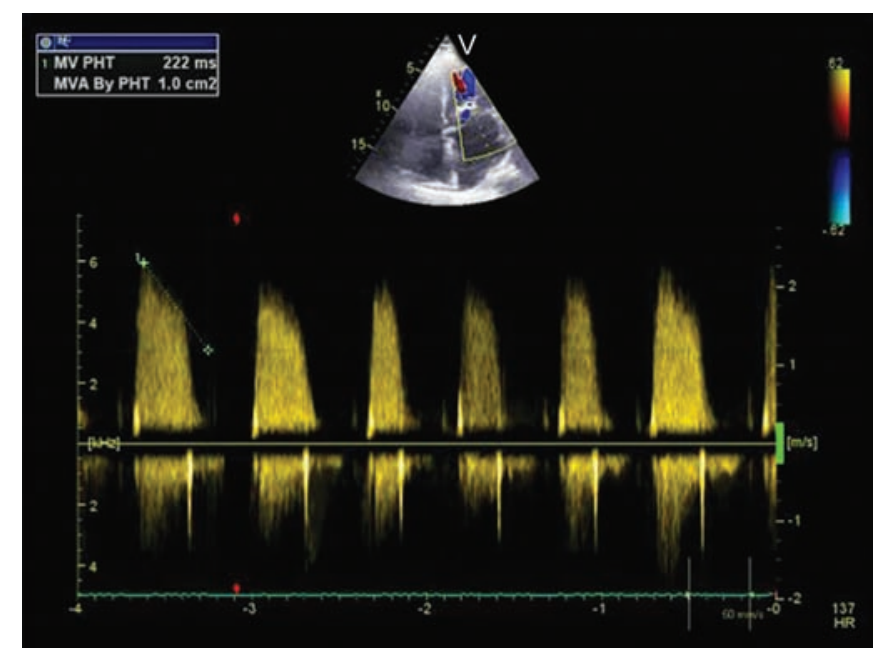

Fig. 6: Estimation of mitral valve area by pressure half time method in a patient with severe mitral stenosis

$$
\begin{aligned}
& \mathrm{SV}(\mathrm{MV})=\mathrm{SV}(\mathrm{LVOT}) \\
& \mathrm{MV} \text { area } \times \mathrm{VTI}(\mathrm{MV})=\mathrm{LVOT} \text { area } \times \mathrm{VTI}(\mathrm{LVOT}) \\
& \mathrm{MV} \text { area }=\pi\left(\mathrm{D}^{2} / 4\right) \times\left(\mathrm{VTI}_{\mathrm{LVOT}} / \mathrm{VTI}_{\mathrm{MV}}\right)
\end{aligned}
$$

Where D is LVOT diameter in $\mathrm{cm}, \mathrm{VTI}$ is velocity time integral in $\mathrm{cm}$.

As multiple measurements are required for calculation, this method is more prone to errors. Note that LVOT diameter measurement is squared in the calculation, thus error in measurement is also squared in final calculations.

Box 5: Continuity equation (key learning points)

- Level 2 recommendation (ASE/EAE guidelines valvular stenosis).

- Based on conservation of mass.

- $\quad$ Prone to errors, because multiple measurements required.

- Not accurate in presence of MR, AR and atrial fibrillation.

5. Proximal isovelocity surface area (PISA) method (Box 6): Proximal isovelocity surface area method can also be used for estimation of mitral valve area and is class II recommendation (combined ASE/EAE guidelines on valvular stenosis). ${ }^{7}$ As blood converges towards an orifice, color Doppler imaging shows concentric shells of similar velocity which corresponds to Nyquist limit/aliasing velocity and can be read from the velocity color scale. Assuming no significant mitral regurgitation, blood flow across the PISA shell is equal to blood flow across the mitral valve.

$$
\begin{aligned}
\text { MV area }= & \pi r^{2} \times V_{\text {aliasing }} / \text { Peak } V_{\text {mitral }} \\
\text { where } \quad \mathrm{r} & =\text { PISA radius, } \\
\mathrm{V}_{\text {aliasing }}= & \text { aliasing velocity at PISA shell read from } \\
& \text { velocity color scale, }
\end{aligned}
$$

Peak $\mathrm{V}_{\text {mitral }}=$ peak diastolic velocity across mitral valve

This method is technically demanding and prone to errors because multiple measurements are required. Also,

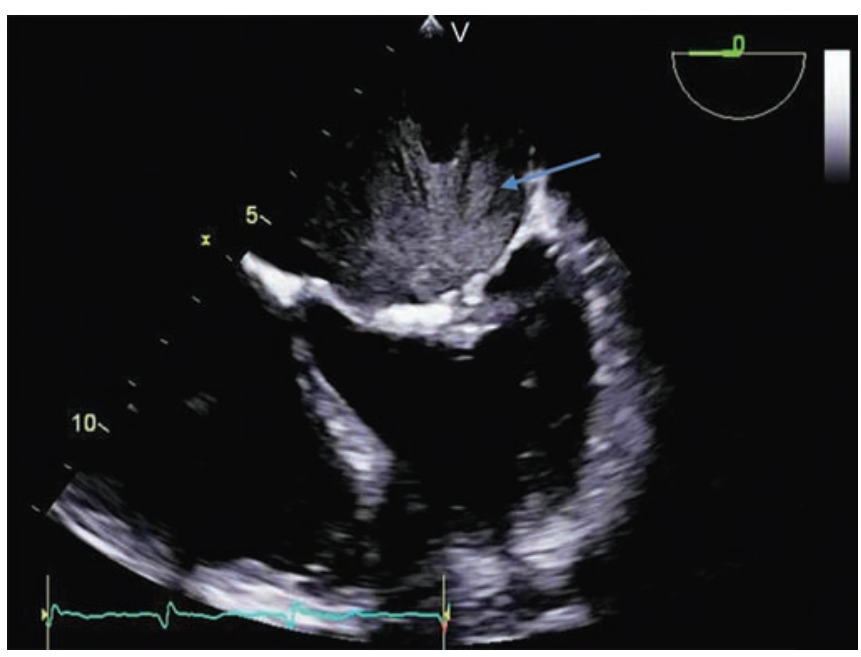

Fig. 7: Midesophageal 4 chamber view (Transesophageal echo) showing spontaneous echocontrast (arrow) in a patient with severe mitral stenosis (Video 5) 


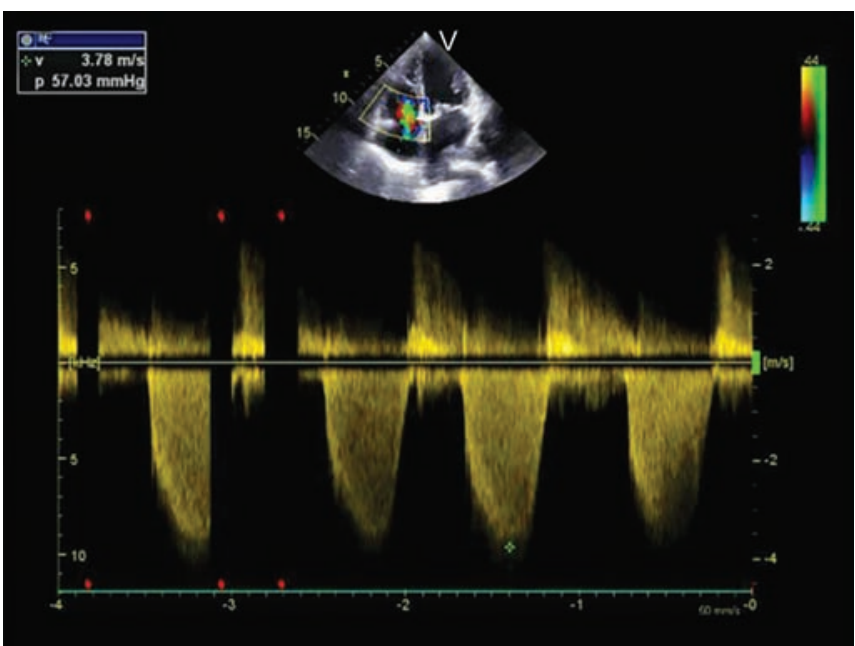

Fig. 8: Estimation of right ventricular systolic pressure (RVSP) or pulmonary artery systolic pressure using tricuspid regurgitation (TR) jet in apical 4 chamber view (transthoracic echo)

an angle correction may be required in case the blood flow direction is not perpendicular to the direction of opening of mitral leaflets.

Box 6: Proximal isovelocity surface area method (key learning points)

- $\quad$ Level II recommendation (ASE/EAE guidelines valvular stenosis).

- Based on conservation of mass.

- $\quad$ Shift the color Doppler scale toward the direction of flow.

- Reduce the Nyquist limit to around $40 \mathrm{~cm} / \mathrm{sec}$.

- Technically demanding

\section{Assessing Valve Morphology}

Assessing the morphology of mitral valve in patients with mitral stenosis is important for planning the intervention required. Percutaneous balloon mitral valvotomy is class I recommendation for patients with symptomatic severe MS (Stage D) and favorable valve morphology. ${ }^{7}$ Presence of more than mild mitral regurgitation, left atrium clot and severely calcified, thickened valve, significant subvalvular disease rule out the option of percutaneous balloon mitral valvotomy in MS patients. ${ }^{15} \mathrm{~A}$ few scores have been described based on leaflet thickening, mobility, calcification and subvalvular thickening to assess the valve for percutaneous valvotomy. ${ }^{16,17}$ However, a detailed description of mitral valve apparatus morphology is more helpful in deciding the intervention of choice than relying on a single scoring system.

Commissural fusion can be assessed in parasternal short axis view while leaflet thickening and mobility can be appreciated in apical 4 chamber and parasternal long axis views. Subvalvular apparatus can also be seen in parasternal long axis and apical views. However, transesophageal echocardiography (TEE) is better for assessment of subvalvular apparatus.

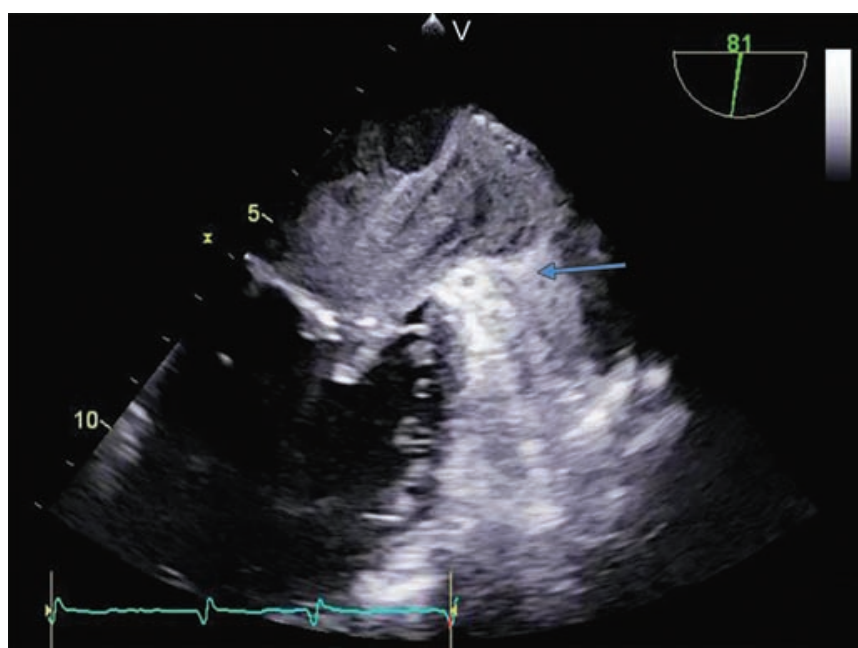

Fig. 9: Midesophageal 2 chamber view (Transesophageal) showing left atrial appendage clot (arrow) in a patient with severe mitral stenosis (Video 6)

\section{Associated Findings}

Left atrium enlargement is a common associated finding as a result of decreased forward flow across the stenotic mitral valve. Spontaneous echocontrast and clot can be seen in left atrium by transthoracic echo but better appreciated by TEE (Fig. 7, Video 5).

Functional tricuspid regurgitation (TR) is commonly associated because of increased right heart pressures but may be due to rheumatic involvement of the tricuspid valve. Tricuspid regurgitation jet can be examined in apical 4 chamber view and application of continuous wave Doppler across TR jet helps in estimating peak pulmonary artery pressures (Fig. 8). Any other associated lesion like involvement of aortic valve and biventricular function should be assessed in every patient.

\section{Role of Transesophageal Echocardiography}

Transesophageal echocardiography is class I recommendation in patients considered for percutaneous balloon mitral valvotomy to rule out LA clot, significant MR and to better assess mitral valve morphology. ${ }^{6}$ Transesophageal echocardiography provides excellent images of mitral valve apparatus and provides additional information which may be missed on TTE. Transesophageal echocardiography is more sensitive than transesophageal echocardiography for detection of LA clot. Midesophageal 2 chamber view is commonly used to look for clot in LA appendage (Fig. 9, Video 6). Valve morphology (leaflet thickening, calcification) can be seen in midesophageal views (Fig. 10, Video 7). Thickened, fused chordae can be appreciated in Transgastric 2 chamber view. All the above described indices for estimating severity can be obtained by TEE as well. Intraoperative TEE is an opportunity to confirm preoperative diagnosis, look for any missed finding, and appreciate associated changes. 


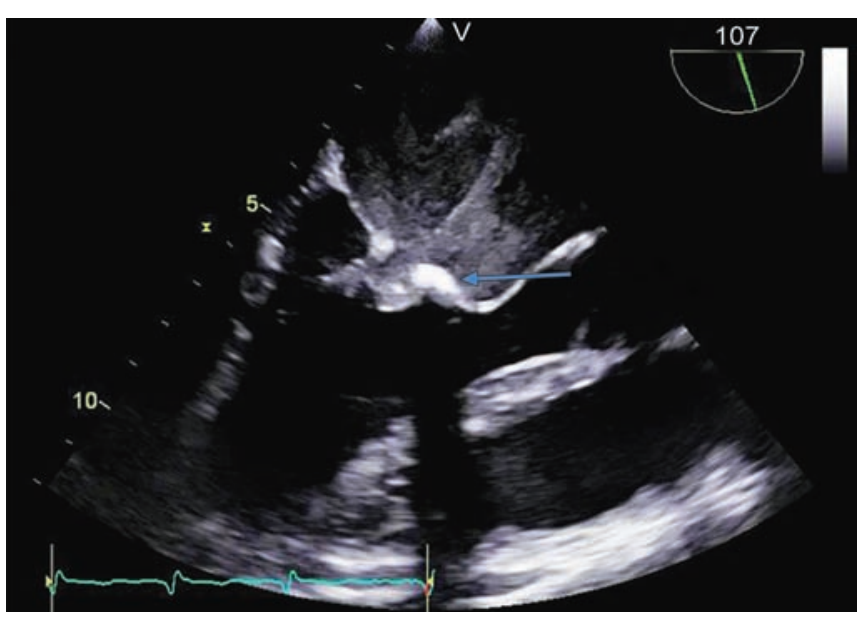

Fig. 10: Midesophageal long axis view showing thickening, calcification at leaflet tips and characteristic diastolic doming of anterior mitral leaflet (hockey stick appearance) (arrow) and spontaneous echocontrast in left atrium in a patient with severe MS (video 7)

\section{Three-Dimensional Echocardiography (Box 7)}

Three-dimensional (3D) echocardiography has the potential to become a new clinical standard in modern era for the assessment of mitral stenosis. With advancements in technology, both transthoracic and transesophageal 3D echo probes are available. Examination of mitral valve apparatus can be done either by real time 3D echocardiography or raw data can be acquired and required images can be cropped afterwards for off-line analysis. Image quality can be improved by increasing the frame rates by opting for acquiring 3D data set from 4 to 6 cardiac cycles, which requires ECG gating. Cessation of respiration, electrocautery is required to prevent stitching artifacts.

Three-dimensional echocardiography is superior than 2D planimetry for accurate measurement of mitral

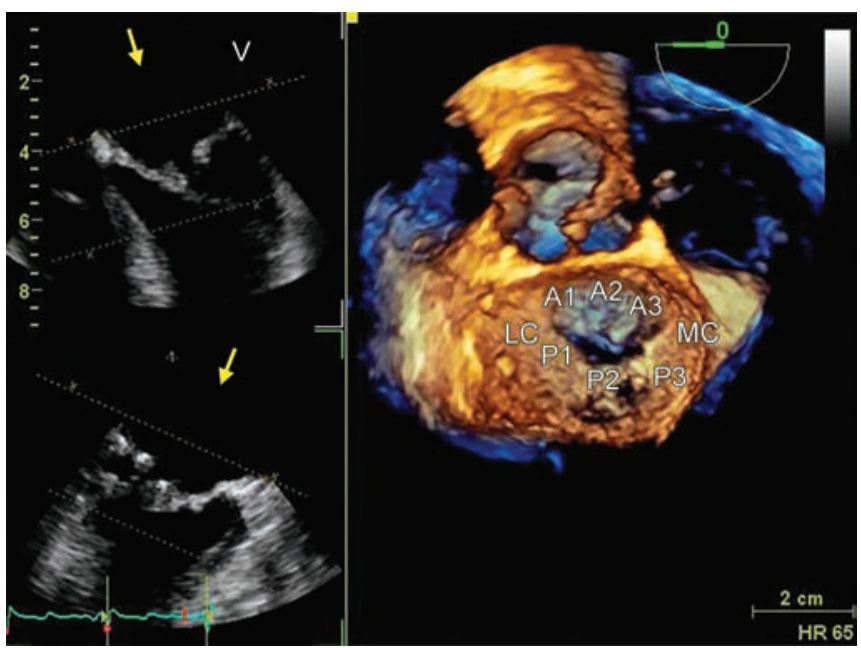

Fig. 12: Three-dimensional enface view of mitral valve (as viewed from left atrium) in a patient with rheumatic mitral stenosis. Please note thickening of anterior and posterior mitral leaflets, reduced mobility of posterior mitral leaflet, fusion of commissures and reduced mitral valve opening. (Video 9). (LC - antero lateral commissure, MC - postero medial commissure)

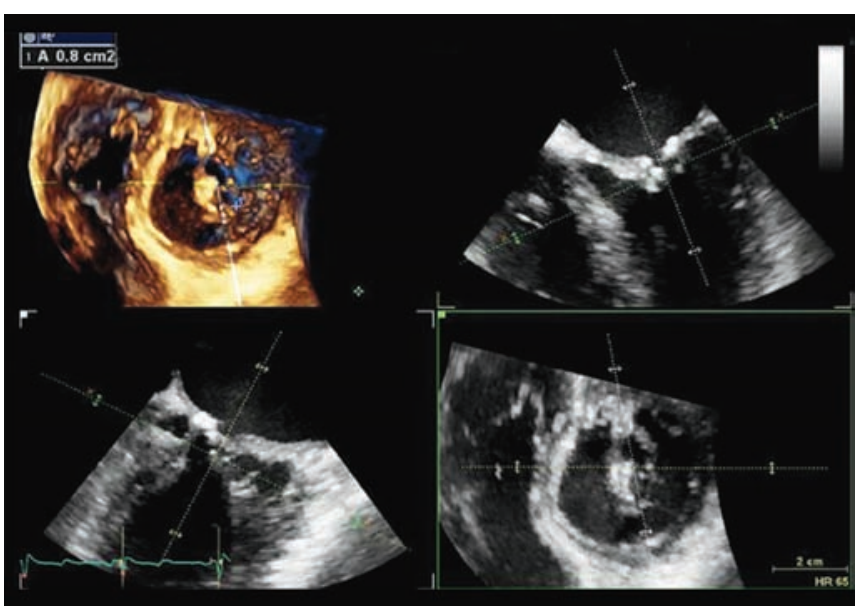

Fig. 11: Three-dimensional echocardiographic assessment of mitral valve area in a patient with rheumatic mitral stenosis. Please note the imaging plane is aligned and placed at tips of mitral leaflets (upper right and lower panel images) and corresponding 3D image obtained (left upper image). Mitral valve area can be easily traced by the in-built software $\left(0.8 \mathrm{~cm}^{2}\right.$ in this case) (Video 8$)$

valve area. While 2D assessment leads to overestimation of mitral valve area, 3D measurements correlate better with invasively derived values in the catheterization laboratory ${ }^{18,19}$ (Gorlin's method). Three-dimensional echocardiography allows better alignment of the imaging plane at mitral leaflet tips, rendering the accurate measurement of the smallest orifice feasible (Fig. 11, Video 8).

A major advantage of 3D echocardiography is the ability to provide full information for mitral valve assessment from single imaging plane, thus avoiding the need of multiple cut section planes required using 2D echocardiography. Three-dimensional echo, especially 3D TEE is now recommended for assessing the morphology for percutaneous balloon mitral valvotomy. It is also

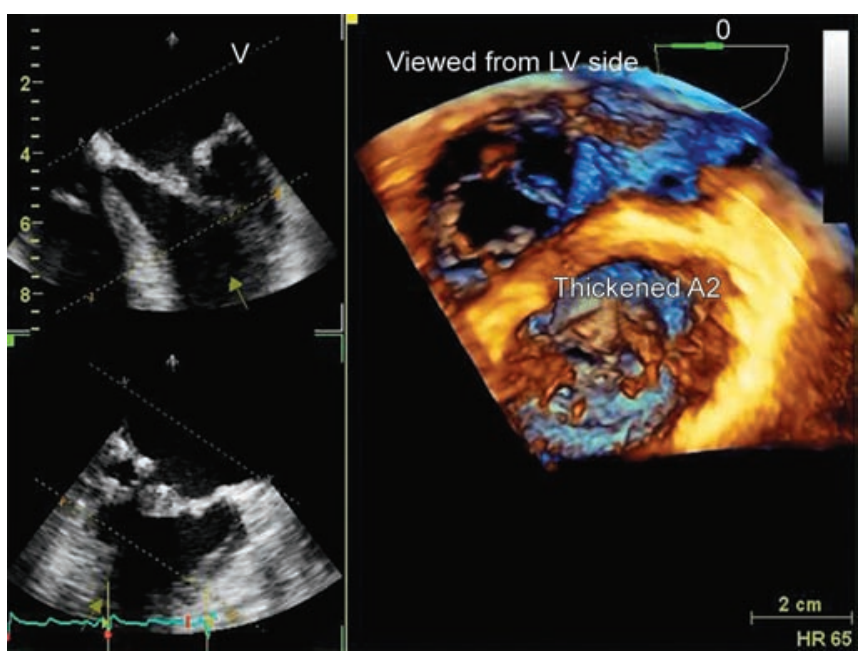

Fig. 13: Three-dimensional echocardiographic view of mitral valve as viewed from left ventricle in a patient with rheumatic mitral stenosis showing thickened A2 segment of anterior mitral leaflet. (Video 10) 


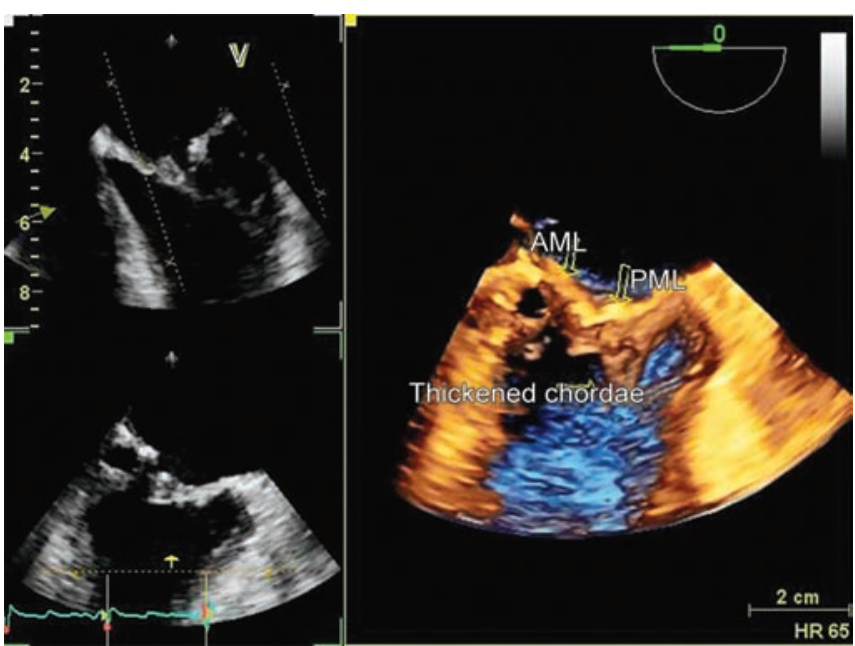

Fig. 14: Midesophageal 4 chamber 3D view on Transesophageal echocardiography showing thickened chordate near the attachment to posterior mitral leaflet. (Video 11). AML and PML - anterior and posterior mitral leaflets respectively

used during the procedure to look for the outcome and complications, if any. There is increased interest nowadays for developing new scores incorporating information from 3D echocardiography for assessing suitability for percutaneous mitral valvotomy. ${ }^{20}$ Threedimensional echo can provide vital morphological information like examination of whole length of leaflets, commissural fusion, extent and distribution of leaflet calcification and chordal thickness and separation (Figs 12 to 14 , Videos 9 to 11 ).

\section{Box 7: Three-dimensional echocardiography} (key learning points)

- $\quad$ Both transthoracic and transesophageal 3D probes available.

- $\quad$ Accurate, reproducible estimation od mitral valve area.

- Allows full assessment of mitral valve apparatus from single imaging plane.

- $\quad$ Better for assessing suitability for percutaneous balloon mitral valvotomy.

- Acquire 3D data set from 4 to 6 cardiac cycles.

- Stop ventilation/respiration and electrocautery temporarily to avoid stitching artifacts.

\section{SUMMARY}

Rheumatic heart disease is the most common cause of mitral stenosis. Transthoracic echocardiography is the imaging modality of choice for establishing diagnosis, assessing severity, associated findings and follow-up. Transesophageal echocardiography provides additional information, especially detection of LA clot and assessing suitability for percutaneous balloon valvotomy. Threedimensional echocardiography is being used more commonly nowadays and allows accurate estimation of mitral valve area noninvasively and also helps in assessing suitability for percutaneous balloon mitral valvotomy.

\section{REFERENCES}

1. Carpentier A. Cardiac valve surgery-the 'French correction. J Thorac Cardiovasc Surg 1983;86(3):323-337.

2. Kumar N, Kumar M, Duran CM. A revised terminology for recording surgical findings of the mitral valve. J Heart Valve Dis 1995;4(1):70-77.

3. Shah P. Intraoperative echocardiography for mitral valve disease. In: Otto CM, Bonow RO, editors. Valvular Heart Disease. 3rd ed. Philadelphia: Saunders Elsevier; 2009: 322-333.

4. Iung B, Baron G, Butchart EG, Delahaye F, Gohlke-Barwolf C, Levang, OW, et al. A prospective survey of patients with valvular heart disease in Europe: The Euro Heart Survey on Valvular Heart Disease. Eur Heart J 2003;24(13):1231-1243.

5. Marijon E, Ou P, Celermajer DS, Ferreira B, Mocumbi AO, Jani $\mathrm{D}$, et al. Prevalence of rheumatic heart disease detected by echocardiographic screening. N Engl J Med 2007;357(5): 470-476.

6. Nishimura RA, Otto CM, Bonow RO, Carabello BA, Erwin III JP, Guyton RA, et al. 2014 AHA/ACC guidelines for the management of patients with valvular heart disease: a report of the American College of Cardiology/American Heart Association task force on practice guidelines. Circulation 2014;129(1):001-235.

7. Bumgartner $\mathrm{H}$, Hung J, Bermejo J, Chambers JB, Evangelista A, Griffin BP, et al. Echocardiographic assessment of valve stenosis: EAE/ASE recommendations for clinical practice. J Am Soc Echo 2009;1(1):1-23.

8. Zamorano J, Cordeiro P, Sugeng L, Perez de Isla L, Weinert L, Macaya C, et al. Real-time three-dimensional echocardiography for rheumatic mitral valve stenosis evaluation: an accurate and novel approach. J Am Coll Cardiol 2004;43(11): 2091-2096.

9. Sebag IA, Morgan JG, Handschumacher MD, Marshall JE, Nesta F, Hung, J, et al. Usefulness of three-dimensionally guided assessment of mitral stenosis using matrix-array ultrasound. Am J Cardiol 2005;96(8):1151-1156.

10. Messika-Zeitoun D, Brochet E, Holmin C, Rosenbaum D, Cormier B, Serfaty JM, et al. Three-dimensional evaluation of the mitral valve area and commissural opening before and after percutaneous mitral commissurotomy in patients with mitral stenosis. Eur Heart J 2007;28(1):72-79.

11. Thomas JD, Weyman AE. Doppler mitral pressure half-time: a clinical tool in search of theoretical justification. J Am Coll Cardiol 1987;10(4):923-929.

12. Schwammenthal E, Vered Z, Agranat O, Kaplinsky E, Rabinowitz B, Feinberg MS. Impact of atrioventricular compliance on pulmonary artery pressure in mitral stenosis: an exercise echocardiographic study. Circulation 2000;102(19):2378-2384.

13. Flachskampf FA, Weyman AE, Guerrero JL, Thomas JD. Calculation of atrioventricular compliance from the mitral flow profile: analytic and in vitro study. J Am Coll Cardiol 1992;19(5):998-1004.

14. Karp K, Teien D, Bjerle P, Eriksson P. Reassessment of valve area determinations in mitral stenosis by the pressure halftime method: impact of left ventricular stiffness and peak diastolic pressure difference. J Am Coll Cardiol 1989;13(3): 594-599.

15. Ben FM, Betbout F, Gamra H, et al. Predictors of long-term event free survival and of freedom from restenosis after 
percutaneous balloon mitral commissurotomy. Am Heart J 2001;142(6):1072.

16. Wilkins GT, Weyman AE, Abascal VM, Block PC, Palacios IF. Percutaneous balloon dilatation of the mitral valve: an analysis of echocardiographic variables related to out-come and the mechanism of dilatation. Br Heart J 1988;60(4):299-308.

17. Vahanian A, Palacios IF. Percutaneous approaches to valvular disease. Circulation 2004;109(13):1572-1579.

18. Min SY, Song JM, Kim YJ, et al. Discrepancy between mitral valve areas measured by two-dimensional planimetry and three dimensional transesophageal echocardiography in patients with mitral stenosis. Heart 2013;99(4):253-258.

19. Schlosshan D, Aggarwal G, Mathur G, et al. Real-time 3D transesophageal echocardiography for the evaluation of rhe-umatic mitral valve stenosis. J Am Coll Cardiol 2011;4(6): 580-588.

20. Anwar AM, Attia WM, Nosir YF, et al. Validation of a new score for the assessment of mitral stenosis using real-time three dimensional echocardiography. J Am Soc Echocardiogr 2010;23(1):13-22. 